\title{
Shifting away from asset damage and towards well-being loss within flood risk management
}

\author{
Koen C. van Hattum ${ }^{1, a}$, Lars T. de Ruig², Matthijs F.M. Bos ${ }^{1}$, Jarl Kind, Hans de Moel ${ }^{2}$ \\ ${ }^{1}$ Royal HaskoningDHV, George Hintzenweg 85, 3068 AX Rotterdam, The Netherlands \\ 2 Institute for Environmental Studies, VU University Amsterdam, Boelelaan 1111, 1081 HV, Amsterdam, The Netherlands \\ ${ }^{3}$ De Waterwerkers, Graaf Floris V weg 3-c, 3739 NA Hollandsche Rading, The Netherlands.
}

\begin{abstract}
Floods can be a cause of poverty. Poverty itself magnifies the impact of floods as poor people are more vulnerable and less resilient. Traditional flood risk assessments (FRAs) focus mostly on asset damages. Yet, poor people own little assets and are often highly exposed to floods. Consequently, traditional FRAs often conclude that it is inefficient to protect the poor and are thus biased against flood risk reduction measures protecting them. The aim of this study is to evaluate FRRIs in a CBA based on the social welfare flood risk reduction benefits. A framework to assess the social welfare flood risk through a Monte Carlo approach is presented herein. A case study illustrates that it is not yet reliable to economically evaluate FRRIs based on the monetized social welfare benefits in CBAs. In addition, a targeted social protection scenario emphasizes the potentially high social welfare benefits that can be realized through risk transfer. Therefore, poverty reduction through risk transfer mechanisms should be considered as a holistic approach to foster socioeconomic growth as such risk transfer mechanisms build socioeconomic resilience in the face of natural disasters. It could have a considerable impact on the lives of people living in vulnerable areas.
\end{abstract}

\section{Introduction}

Floods are devastating climate hazards, leading to substantial economic losses and human suffering. There are 70 million people exposed to floods globally with 19,000 people killed, 12,000 critically injured and 150,000 rendered homeless on average per year (Doocy et al., 2013; UNDRR, 2019). These figures will only increase in the future due to a combination of climate change, populationand economic growth (Hirabayashi et al., 2013; McGranahan et al., 2007). Low-lying coastal zones are often inhabited by people with a lower socioeconomic status. They are highly exposed and vulnerable as they often lack protection and evacuation possibilities (Winsemius et al., 2018). The estimations of people living in these low-lying regions range from 0.6 billion people at present, up to $1.0-1.4$ billion people in 2060 , of which $80 \%$ in developing countries (Islam et al., 2013; Neumann et al., 2015).

Uncertainties in sea level rise projections pose a challenge to flood risk management (FRM) as flood risk reduction measures (FRRMs) often require large capital investments over a long period of time. Decision makers are cautious to make suboptimal, irreversible choices as they are aware of these uncertainties (de Ruig et al., 2019). As a result, decisions are often postponed until the next hazard strikes the region (Aerts et al., 2018). Therefore, it is important to rationalize these investments through economic evaluation techniques to legitimize flood risk reduction investments (FRRIs).

Cost-benefit analysis (CBA) is a powerful tool for public decision makers to economically evaluate probable strategies in FRM and disaster risk reduction. The renowned English and French economists Dupuit, Marshall and Pigou first introduced CBA in Europe in the $19^{\text {th }}$ Century (Andersson, 2018; Porter, 1995). Nowadays, rational approaches to evaluate public investments in FRRMs become even more important as climate change mitigation funds are finite (Kind et al., 2017).

Traditional FRAs and CBAs take financial values into account and focus on physical damage to buildings and assets, irrespectively of who uses or owns them. In this case, exposure, susceptibility and coping strategies form a function of physical vulnerability. The total flood risk is expressed in expected annual damage (EAD) and is calculated based on flood damages and probabilities (Kind et al., 2019). Yet, poor people own little assets and are often highly exposed to floods. Traditional FRAs and CBAs therefore tend to conclude that it is inefficient to protect the poor. However, the objective of most governments and donors is to improve or maximize social welfare, which comprises the well-being of all individuals

\footnotetext{
a Corresponding author: koen.van.hattum@rhdhv.com

DOI 10.3311/ FLOODRisk2020.11.20
} 
in a society. Therefore, such traditional methods are often unsuitable to legitimize public FRRIs.

Social welfare FRAs and CBAs focus on the impact of a flood on the well-being of an individual. In social welfare economics, well-being is related to consumption through the utility function (Kind et al., 2017, 2019). The concept of utility was introduced by economists to operationalize well-being, which is determined by wealth, income or consumption. The relationship is non-linear and is well-known as the 'diminishing marginal utility of income'. This means that increments in consumption within a population imply different proportions of decreasing well-being. It also legitimizes the use of equity weights in CBAs, which indicates that a dollar for poor people receives a higher value than for non-poor people (Kind et al., 2017). Therefore, there is a need for social welfare FRAs and CBAs, that take a societal perspective. In these social welfare FRAs and CBAs, all costs and benefits are valued on the basis of willingness-to-pay or willingness-to-accept. Social vulnerability and income inequality are both considered, which means that the damages of less vulnerable and non-poor people are valued lower than for more vulnerable and poor people (Kind et al., 2019). Especially in the case of developing countries, the people with the lowest socioeconomic status are the most vulnerable and live in the areas most at risk. Traditional FRAs and CBAs that do not incorporate social vulnerability and income inequality could therefore reach different conclusions compared to social welfare FRAs/CBAs.

Social vulnerability has already been incorporated in some FRM studies (Cutter et al., 2013; Zang \& You, 2013; Koks et al., 2015). In these papers, the Social Vulnerability Index (SoVi) was used to jointly assess the hazard, exposure and social vulnerability. It appeared that social vulnerability to floods is a heterogonous phenomenon within the population and between areas. FRRM's should therefore be tailored to local characteristics. In this paper we therefore apply the social welfare approach of Kind et al. (2019) that incorporates social flood vulnerability. We apply this model to an extensive case study to evaluate FRRIs in a CBA based on the social welfare flood risk reduction benefits and CBA parameters.

One way to reduce flood risk is to offer physical flood protection through for example the construction of dikes or levees. Pre- and post-disaster risk transfer mechanisms are alternative FRRMs that can either make people less vulnerable before a flood or help people recover more quickly after a flood. This paper examines the possibilities of pre- and post-disaster risk transfer mechanisms as they are able to mitigate the impact of floods on an individual's consumption, and hence wellbeing.

Recent research has already tried to estimate wellbeing loss in the face of natural disasters as a measure of disaster severity (Markhvida et al., 2020; Walsh \& Hallegatte, 2020). However, these assessments use aggregated data at the census tract level. As a result, the heterogeneity in the distribution of household characteristics may not be captured. To overcome this problem, this research applies a Monte Carlo approach to assess the flood risk. Probability distributions of the most critical flood risk parameters are used to determine the social flood vulnerability and compute the social welfare loss per individual.

\section{Methodology}

Traditional FRAs (left frame of Figure 2) are based on asset damages and are calculated based on the hazard (the inundation depth), exposure (the asset) and vulnerability (the damageability of the asset). This results in a total flood risk of an area and is expressed in EAD.

In this paper, we adopt the social welfare flood risk model from Kind et al. $(2017,2019)$ which is visualized in the right frame of Figure 2. This model also considers the impact of a flood on the well-being of individuals as wellbeing is based on consumption and is described by the utility function.

\subsection{The utility function}

The utility function is governed by the law of diminishing marginal utility of consumption, is non-linear and has a concave shape. This indicates that with decreasing consumption, the marginal utility or well-being increases (Figure 1) (Kind et al., 2017). In this paper, we assume that the annual income of an individual is consumed in the same year. Annual consumption is therefore equal to annual income. Diminishing marginal utility of consumption is essential to social welfare FRAs in two ways. First, it provides an explanation why people tend to be risk averse: an additional unit of consumption has a greater value during periods when consumption is considered low than during periods when consumption is considered high. Second, it justifies the use of equity weights in CBAs where an additional unit of consumption is valued higher for poor people than for non-people (Kind et al., 2017). The utility function is described in Eq. 1.

$$
U(C)=\frac{C^{1-\gamma}}{1-\gamma}
$$

For $\gamma \geq 0$ and $\gamma \neq 1$, where $U$ is the utility, $C$ is the consumption and $\gamma$ the elasticity of marginal utility of consumption. The well-being, defined by the utility, is linear if $\gamma=0$. For $\gamma \geq 0$, the marginal utility of consumption diminishes, resulting in a concave shape of the utility function (see Figure 1).

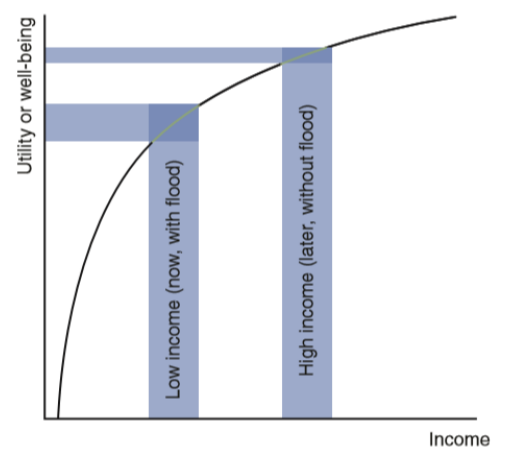

Figure 1: The utility function: An equivalent decrease in income results in a different decrease in utility or well-being based on the initial consumption level (Kind et al., 2017). 


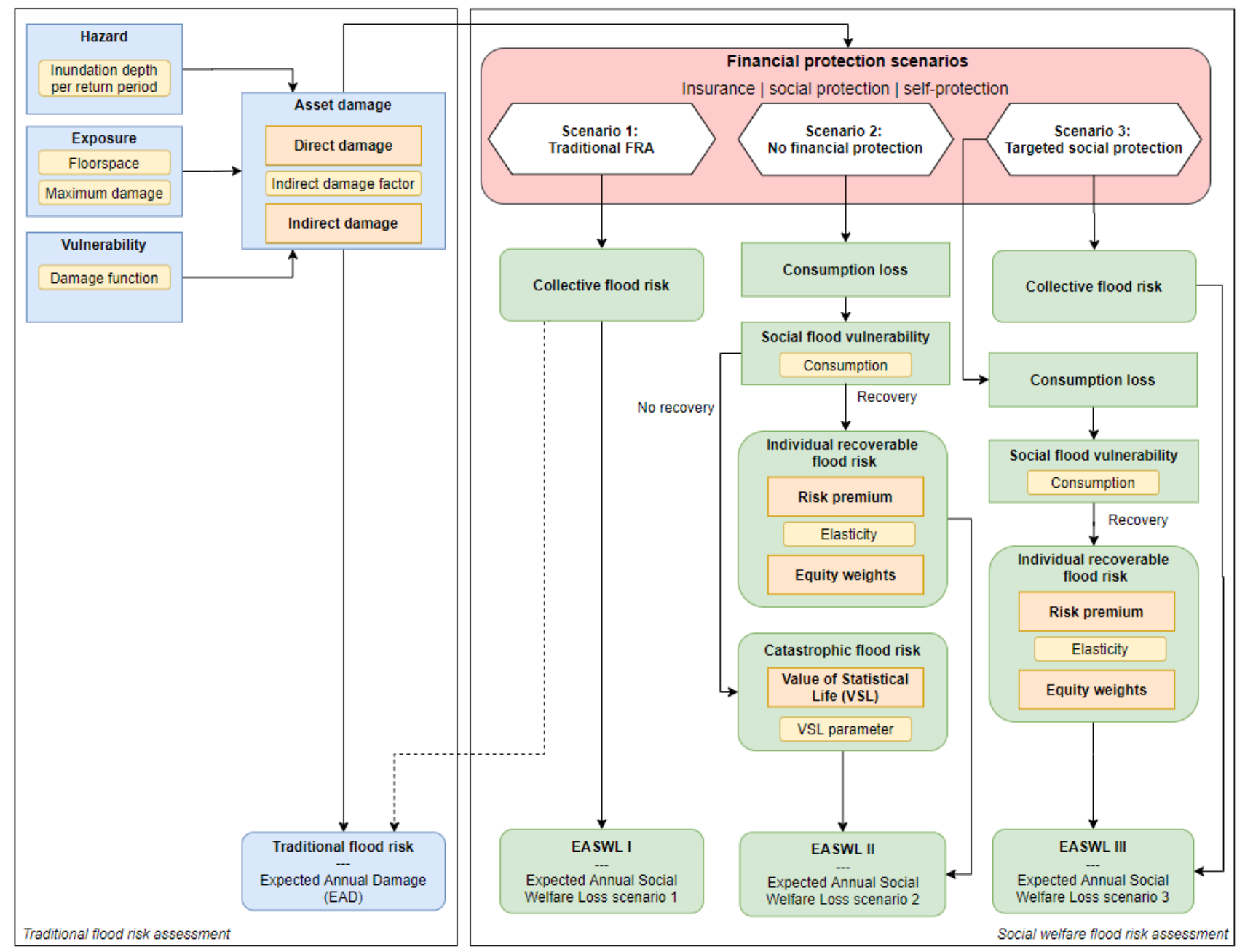

Figure 2: Flow chart of the methodology. All blue coloured boxes are part of a traditional FRA whereas all green coloured boxes are part of a social welfare FRA. The grey boxes are part of the CBA. Yellow boxes with rounded-corners represent input variables or parameters. Orange boxes are calculated values based on input from variables, parameters or other boxes. Large rounded-corner squares represent the different types of flood risk. The large red rounded-corner box contains the three different financial protection scenarios. The social welfare framework is adopted from Kind et al. $(2017,2019)$.

\subsection{Financial protection}

Consumption loss is the damages that is not covered through financial protection. Without any form of financial protection, we assume that floods lead to an immediate reduction of consumption and hence well-being as the repair or replacement of damaged assets or goods are financed at the cost of consumption. There are three forms of financial protection that can mitigate the immediate impact of floods on consumption or smooth it over time: insurance, social protection and self-protection.

Insurance is a form of financial protection in which individuals can smooth the impact of a flood over time by paying an annual insurance fee. In case of a flood, damage repairs are paid by the insurer.

Social protection is a form of financial protection that is provided by the national government, international community, NGOs, philanthropists, relatives and/or friends. It comes in the form of social-assistance, compensation of emergency aid (Kind et al., 2019).

Self-protection is a form of financial protection in which an individual can smooth the impact of a flood over time by using savings, borrow money or sell goods or assets. Individuals with lower socioeconomic status are generally less well self-protected as they have a lower income, do not have access to the credit market or own little assets (Hallegatte et al., 2016, 2017; Zakour \& Gillespie, 2013).

\subsection{Types of flood risk}

If all damage is covered through insurance or social protection, we assume that individuals do not experience any well-being loss as damages are spread over large groups and/or time. In this case, social welfare flood risk is equal to traditional flood risk, which is expressed in EAD. This is what Kind et al (2019) call collective flood risk.

The social flood vulnerability is assumed to be the consumption loss as a fraction of annual consumption by Kind et al. (2017). It defines of individuals are able to recover from a flood. If the social flood vulnerability is less than 1, Kind et al. (2019) assume this is individual recoverable flood risk. In this case, consumption loss is translated into a social welfare value based on risk 
premium and equity weights, which is described extensively in Kind et al. (2017, 2019).

If the social flood vulnerability exceeds the critical threshold of 1 when consumption loss is equal or larger than annual consumption, Kind et al. (2019) assume catastrophic flood risk. In this case, the individual cannot recover anymore. Kind et al. (2019) applies a Value of Statistical Life (VSL) as a proxy.

\section{4 financial protection scenarios}

Due to the general lack of data on all three forms of financial protection, Kind et al. (2019) estimate the social welfare flood risk under three different financial protection scenarios (see the red rounded-corner square in Figure 2). In this paper we adopt these financial protection scenarios:

(1) In the first scenario we assume that damage of individuals is fully covered through insurance. Individuals that have sufficient financial protection experience hardly any social welfare loss as damages are spread over large groups and/or time. The social welfare loss in scenario 1 is equal to the value of traditional flood risk as the individual recoverable flood risk per individual is small and EAD is therefore a right way to express the flood risk. Scenario 1 thus only consists of collective flood risk.

(2) In the second scenario we assume no form of financial protection through insurance, social- or selfprotection. The consumption loss is therefore equal to the flood damage in the year of the flood. In this case, there is no collective flood risk and residential flood risk consists of individual recoverable and catastrophic flood risk. If the social flood vulnerability is less than 1 , risk premium and equity weights will determine the value of the social welfare flood risk. If the consumption loss is higher than the annual consumption of an individual, the social flood vulnerability becomes larger than 1 and reaches infinity. In this case, individuals will face catastrophic flood risk and recovery is impossible. This may cause serious issues involving lasting poverty, personal bankruptcy (Lawless, 2005), starvation (Naqvi \& Rehm, 2014) or infant mortality (Anttila-Hughes \& Hsiang, 2013).

(3) In the third scenario we assume a situation where all individuals should maintain a minimum annual consumption after a flood. The consumption loss is assumed to be smoothed over 5 years and the minimum consumption is set at US\$ 700 , which is the poverty line. If consumption was already below the poverty line, this level of consumption is set as the minimum. Individuals will thus receive social protection to prevent them from experiencing catastrophic flood risk. In this case, the social welfare flood risk consists of collective flood risk (the consumption loss that is compensated through social protection) and individual recoverable flood risk (the remaining consumption loss).

\subsection{Cost-benefit analysis}

The FRRMs are economically evaluated in a CBA. The avoided expected damage represents the benefit, and the FRRIs and operation and maintenance (O\&M) expenditure represent the costs. A more elaborate explanation on the FFRIs is provided in section 3.4. The Net-Present Value (NPV) is calculated by Eq. 2 :

$$
N P V=\sum_{t=1}^{T} \frac{\left(B_{t}-C_{t}\right)}{(1-r)^{t}}
$$

Where $B_{t}$ is the benefit of the FRRM in year $t, C_{t}$ the cost, $r$ the net discount rate of the economic growth rate and the discount rate, and $T$ the lifetime of the project in years. The benefit is the avoided annual damage in year $t$ and costs are the sum of the investment and O\&M expenditure in year $t$. A positive NPV indicates that the discounted benefits are larger than the discounted costs and therefore implies that a certain FRRM generates a net economic benefit. The Benefit-Cost Ratio (BCR) is calculated by dividing the discounted benefits by the discounted costs (Eq. 3):

$$
B C R=\frac{\sum_{t=1}^{T} \frac{B_{t}}{(1+r)^{t}}}{\sum_{t=1}^{T} \frac{C_{t}}{(1+r)^{t}}}
$$

The BCR is thus higher than 1 if the NPV is positive. Both indicators are provided since the BCR gives insight in the relative economic benefit per dollar invested whereas the NPV indicates the total economic benefit that a FRRM generated on the long term.

\section{Case study}

To demonstrate the social welfare approach in CBAs by Kind et al $(2017,2019)$, We apply it to Tien Lang in Vietnam based on the data from the World Bank Coastal Resilience Project that was carried out by Royal HaskoningDHV (2019a).

Tien Lang is one of the six coastal districts located within the Hai Phong Province. It has a relatively short coastline of $17 \mathrm{~km}$. The total area of the district is $189 \mathrm{~km}^{2}$, of which $146 \mathrm{~km}^{2}$ is located between dikes. About $70 \%$ of the total area consists of used land $(90 \%$ of the area that is located within the dike system), inhabited by 155,000 people, mainly in rural areas. Only $10 \%$ of the population lives in urban areas. Tien Lang is located in the Red River Delta and is enclosed by three branches of the Red River: in the north / northeast by the Van Uc River; in the south / southwest by the Thai Binh River; and in the southwest by the Mia River. The East Sea forms the eastern border which extends towards the southeast.

Tien Lang is one of the most storm-prone areas in Vietnam, with the most severe storms occurring from July to September. The region is affected by three to five storms each year, with one or two storms hitting the area directly. A system of coastal and river dikes surrounds Tien Lang to reduce the flood risk. Being surrounded by dikes, Tien Lang is essentially a polder in the Red River Delta. The dike system along the coastal boundary creates a freshwater and saline system, thereby creating a clear distinction between ecosystems on the seaward side of the 
coastal dike and ecosystems inside the coastal and riverine dike. Figure 3 provides an overview map of Tien Lang.

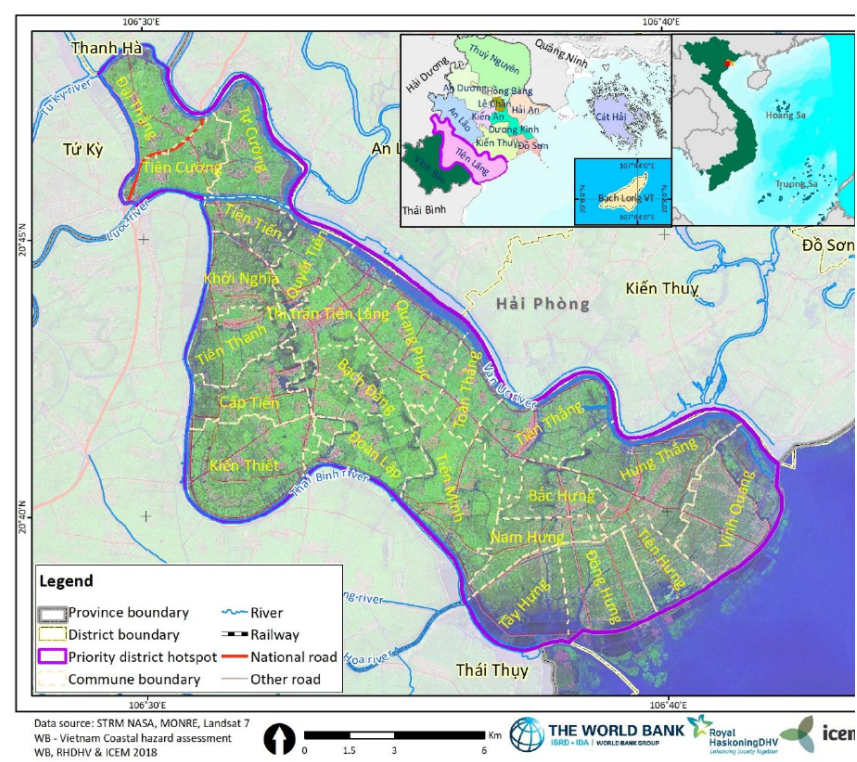

Figure 3: Overview map of Tien Lang. The proximity of Tien Lang within Vietnam is indicated in the top right map with red (Royal HaskoningDHV, 2019a)

\subsection{Flood hazard assessment}

The climate change scenario adopted in this research follows the RCP 8.5 projections of the Intergovernmental Panel on Climate Change (IPCC, 2013). Sea level rise defined in this climate change scenario is $13 \mathrm{~cm}$ in 2030 . Next to SLR, this research also considers future rainfall change projections. The assumed increase in rainfall is estimated to be $12 \%$ in 2030 (Royal HaskoningDHV, 2019a).

To estimate the flood hazard, hydraulic modelling for various return periods (10, 30 and 100 years) has been applied to determine inundation due to pluvial, fluvial and coastal flooding. Royal HaskoningDHV (2019a) shows that Tien Lang is most prone to fluvial flood hazards due to breaches in the river dikes, followed by coastal flooding due to breaches in the coastal dike. The results of the different flooding conditions causing inundation are aggregated to find the inundation depths that are statistically representative for each return period. The inundated areas vary from 2,200 ha (12\% of the total area) for the 10 years return period, to 12,400 ha $(65 \%$ of the total area) for the 100 years return period.

\subsection{Social welfare FRA}

Damages to residential areas are directly suffered by individuals and thus only induce well-being loss. Therefore, flood risk is divided into residential and nonresidential. Non-residential flood risk is estimated through conventional land-use-based damage calculations and is adopted from Royal HaskoningDHV (2019a).

Contrary to the way non-residential flood risk is estimated as described in the above, residential flood risk is estimated through a Monte Carlo approach as risk parameters to compute social flood vulnerability and flood risk per individual are not known. A synthetic population of 10,000 individuals is formed based on the probability distributions of inundation depth, floorspace and annual consumption. The social flood vulnerability and the social welfare loss per individual are then computed per commune. The average of every type of residential flood risk is finally multiplied by the number of affected individuals per commune. The EASWL is the sum of the residential and non-residential flood risk.

The social welfare FRA inputs are summarized in Table 1 and are all included in the flow chart of the methodology as set out in Figure 2.

\begin{tabular}{|l|l|c|}
\hline Item & Source & Range \\
\hline Inundation depth & Royal HaskoningDHV (2019a) & $0-2.9 \mathrm{~m}$ \\
\hline Floorspace & 2009 Census - (GSO, 2010) & $4.1-20.7 \mathrm{~m}^{2}$ \\
\hline Consumption & Lanjouw et al. (2013) & US\$ 234-4,267 \\
\hline Indirect damage & Royal HaskoningDHV (2019a) & $50 \%-150 \%$ \\
\hline Damage function & Huizinga et al. (2017) & $0-1$ \\
\hline Maximum damage & Huizinga et al. (2017) & US\$ $143-303$ \\
\hline $\begin{array}{c}\text { Utility function - } \\
\text { Elasticity }\end{array}$ & Kind et al. (2019) & 1.2 \\
\hline VSL & Reynaud \& Nguyen (2016) & $77-111$ \\
\hline Population map & Worldpop (2020) & - \\
\hline Land use map & Royal HaskoningDHV (2019a) & - \\
\hline
\end{tabular}

Table 1: social welfare FRA inputs with source and range.

The damage function has been derived based on the Joint Research Centre report of Huizinga et al. (2017), complemented by a Royal HaskoningDHV reference project in Sri Lanka (Royal HaskoningDHV, 2019b) and the Dutch HIS-SSM study (de Bruijn et al., 2015). The damage factors have a threshold of $20 \mathrm{~cm}$ to account for model uncertainties, physical barriers and the general opinion that a few $\mathrm{cm}$ of inundation will not cause damages (following Scussolini et al. (2017)).

The maximum damage has been obtained from Huizinga et al. (2017). The values are country specific and are based on the GDP relationships. The value has been corrected for inflation until 2018. The mean maximum damage is set at $198 \mathrm{US} \$ / \mathrm{m}^{2}$, with a range between US\$ 143-303.

The indirect damage is considered to be triangularly distributed between $50 \%$ and $150 \%$ of the direct damage.

The inundation depths per return period are taken from Royal HaskoningDHV (2019a). A hydraulic coupled 1-2D Mike FLOOD model software was used to simulate both the flows in the river channels (1D Mike 11) and over the ground surface (2D Mike 21) with the rainfall and surge. The flood assessments include three types of hazards that cause inundation: pluvial, fluvial and coastal with a return period of 10,30 and 100 years. The DEM that was applied has a resolution of $30 \mathrm{~m} \times 30 \mathrm{~m}$. An inundation scenario is presented for 2030 .

The distribution of floorspace per individual are based on the 2009 Vietnam Population and Housing 
Census. It is the most recent census available as the periodicity of Vietnam's census is 10 years. The consumption distributions are based on the underlying data of Vietnam's poverty map (Lanjouw et al., 2013). The annual consumption per individual is corrected for inflation until 2018 with an average rate of $3 \%$. The spatial distribution of population is derived from the open-source database of the University of Southampton (Wordpop, 2017).

Risk premium and equity weights both have the elasticity of marginal utility as an input parameter. In literature, suggested values for elasticity are in the range of 0.5-2.0. This research applies a central value for elasticity of 1.2. A more detailed overview of the different elasticities can be found in Kind et al. (2017). The VSL parameter implemented in this research ranges from 77 to 111 (Reynaud \& Nguyen, 2016).

\subsection{Cost-benefit analysis}

To prevent Tien Lang from flooding, Royal HaskoningDHV (2019a) proposed FRRMs with a safety standard of 30 years based upon their risk assessment. Total costs of investments to protect Tien Lang from floods with a return period of 30 years are estimated at US\$ 8.8 million. Other direct costs for these projects include O\&M costs estimated to be $0.1 \%$ of capital cost per year (Aerts, 2018).

The discount rate in this study is set at $6 \%$. The economic growth rate is varied between $3 \%, 6 \%$ and $9 \%$, representing a factor $0.5,1.0$ and 1.5 of the present growth rates. This provides insight into the sensitivity of this parameter. The lifetime of the CBA is set at 30 years.

\section{Results}

\subsection{Scenario 1 - Traditional FRA}

In the first scenario, damage of individuals is fully covered by insurance. This means that no individual will experience consumption loss. In this case, there is no individual recoverable flood risk and catastrophic flood risk and residential flood risk only consists of collective flood risk. It is however an unlikely scenario for Vietnam, since flood insurance penetration is low (Reynaud et al., 2018) and the Vietnamese government only provides social protection up to a maximum of US\$ 300 per household (World Bank, 2010). The results are summarized in Table 2.

\begin{tabular}{|cc|c|c|c|}
\hline Item & & Scenario 1 & Scenario 2 & Scenario 3 \\
\hline Residential flood risk & 1.7 & 54.4 & 1.6 \\
$-\quad \begin{array}{ll}\text { Collective } \\
\text { risk }\end{array}$ & 1.7 & 0 & 0.9 \\
$-\quad \begin{array}{ll}\text { Individual } \\
\text { recoverable flood } \\
\text { risk }\end{array}$ & 0 & 1.2 & 0.7 \\
& 0 & 53.2 & 0 \\
\hline
\end{tabular}

\begin{tabular}{|l|c|c|c|}
\hline $\begin{array}{l}\text { Catastrophic flood } \\
\text { risk }\end{array}$ & 1.2 & 1.2 & 1.2 \\
Non-residential flood risk & 1.5 & 18.6 & 1.4 \\
\hline Direct EASWL & $\mathbf{2 . 9}$ & $\mathbf{5 5 . 6}$ & $\mathbf{2 . 9}$ \\
\hline Total EASWL & $100 \%$ & $0 \%$ & $57 \%$ \\
\hline Financial protection rate &
\end{tabular}

Table 2: Social welfare flood risk results of all three financial protection scenarios. All values are in $\mathrm{M} \$$

The size of the affected population has been calculated based on the flood extent areas overlaying the spatial distribution map of Tien Lang. A wide range from 3-55\% of the population is at risk, depending on the return period of the flood hazard. The number of people that is annually expected to be affected is about 6.000 , which indicates that every year $4 \%$ of the population has a chance of experiencing a flood, on average. This number will only increase as both the flood extent and flood depth increase due to climate change.

As this scenario is equal to a traditional FRA, the validity of the Monte Carlo approach can be examined by comparing the EAD reported by Royal HaskoningDHV (2019a) and the EASWL of this research. The conventional land-use-based damage calculations of Royal HaskoningDHV (2019a) yielded a total EAD of US\$ 2.6 million, based on $100 \%$ indirect damage of the direct damage. It is close to the total EASWL of US\$ 2.9 million and falls within the calculated EASWL uncertainty range of US\$ 1.0-10.6 million.

Figure 4 shows a map with the total EASWL per commune. The highest social welfare flood risk is found in the communes with the highest land use values in combination with the highest inundation depths.

The communes located along Thai Binh River face the highest risk (i.e., Kien Thiet, Cap Tien, Tien Thanh, Khi Nghai, Tien, Quyet Tien), followed by the coastal communes (i.e., Tay Hung, Dong Hung, Vinh Quang, Hung Thang). The commune Quang Phuc remains completely prevented from flooding because the average elevation of this commune is relatively high compared to the other communes.

If FRRMs should increase the safety standard to the 30-year flood level for the whole district, the annual flood risk reduction benefit would be US\$ 1.0 million. This would result in a total PV benefit of US\$29.2 million over the whole lifespan of the project (assuming an economic growth rate and discount rate of both $6 \%$ ).

\subsection{Scenario 2 - No financial protection}

The second scenario assumes no form of financial protection. In this case, there is no collective flood risk and residential flood risk consists of individual recoverable and catastrophic flood risk. Catastrophic flood risk is estimated through the VSL. For Vietnam, this comes down to roughly US\$65,000 per individual. The results are summarized in Table 2. 


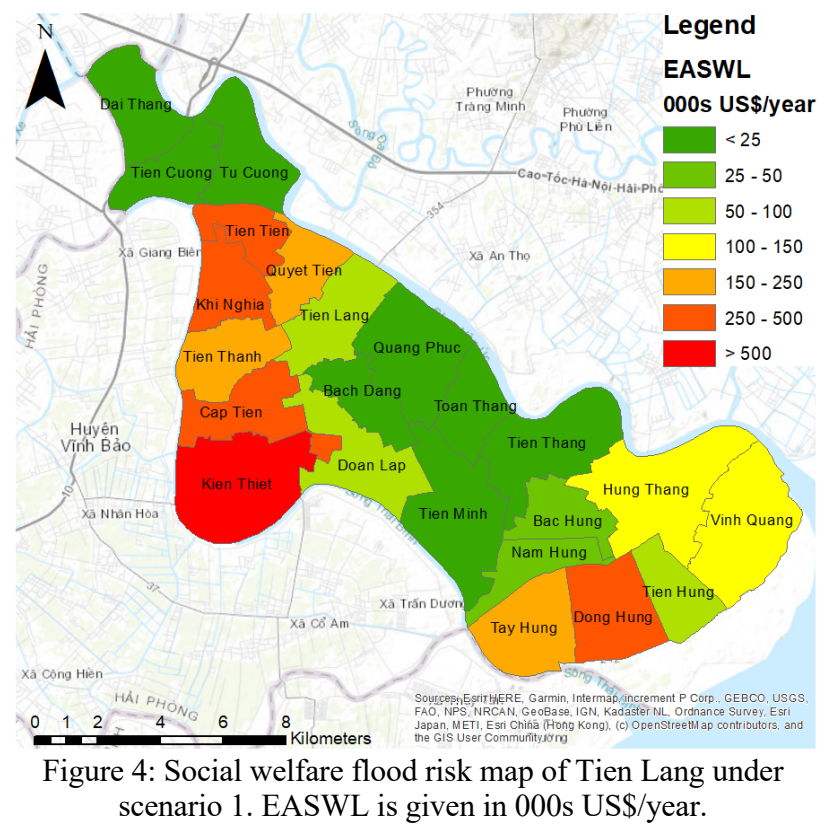

Residential flood risk is the sum of individual recoverable and catastrophic flood risk and amounts to US\$ 54.4 million. Individual recoverable flood risk is the expected social welfare loss of the damage that is restored at the cost of consumption and comes down to US\$ 1.2 million. By far the largest part of residential flood risk consists of catastrophic flood risk, which amounts to US\$ 53.2 million. Non-residential flood risk is equal to US\$ 1.2 million. The total Expected Annual Social Welfare Loss (EASWL) sums up to US\$ 55.6 million. This suggests that the social welfare flood risk between full and no financial protection differs with a factor 18 . In theory, FRRIs targeting poor people would be accepted immediately because the large social welfare benefit due to the absence of financial protection justifies the investments. The large difference in social welfare flood risk between scenario 1 and scenario 2 also indicates that flood risk may seriously be underestimated in a traditional FRA. FRAs that do not take financial protection and social flood vulnerability into account, should therefore be interpreted with caution. The flood risk of poor people may be severely underestimated as poor people are likely to be the most vulnerable and the least financially protected. Moreover, CBAs based on these social welfare benefits will be biased against FRRIs to protect the poor.

Figure 5 shows a map with the total EASWL per commune. The highest social welfare flood risk is found in the communes with the highest amounts of damages in combination with the lowest annual consumption per individual. The communes along Thai Binh River face the highest risk, followed by the coastal communes.

The large contribution of catastrophic flood risk to the total social welfare flood risk $(96 \%)$ is a result of the fact that a vast amount of the affected population has a social flood vulnerability of 1 or higher. The percentage of the total affected population that faces catastrophic flood risk ranges from $0.1-26 \%$, depending on the return period of the flood hazard.

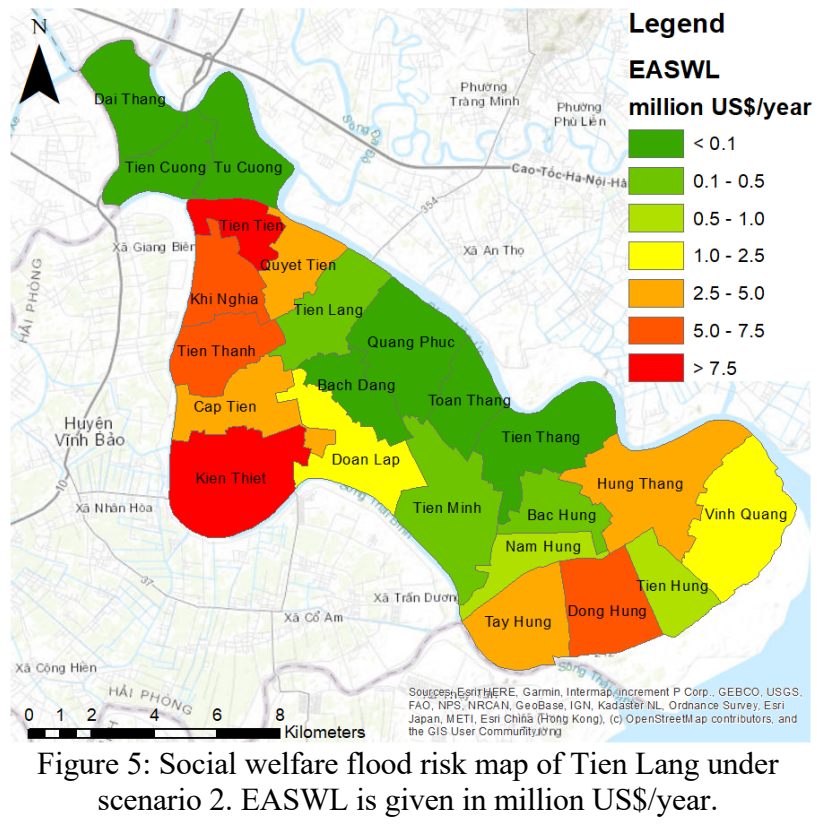

The annual number of expected people suffering catastrophic flood risk is about 750. This indicates that, on average, every year $12 \%$ of the annual affected population has a chance of experiencing catastrophic flood risk. Figure 6 shows the percentages of the population per commune that encounters catastrophic flood risk in a 100year flood event. Large percentages of catastrophic flood risk (> 45\%) are to be found in the coastal communes and the communes located along Thai Binh River. There are five communes that do not encounter any catastrophic flood risk due to a social flood vulnerability less than 1 as damage caused by lower inundation depths does not exceed annual consumption.

If FRRMs should increase the safety standard to a 30-year flood level for the whole district, the annual flood risk reduction benefit would be US\$ 17.3 million. This would result in a total PV benefit of US\$ 518.6 million over the whole lifespan of the project (assuming an economic growth rate and discount rate of both $6 \%$ ). It is assumed that all individuals that encounter catastrophic flood risk will eventually face death as an indirect cause of flooding. This would mean that roughly 20,000 people die in case of a 100-year flood event. In practice, this would not happen as the Vietnamese Government and international community are likely to interfere with social assistance if such human catastrophe was about to happen (World Bank, 2017).

\subsection{Scenario 3 - Targeted social protection}

In the third scenario, it is assumed that consumption loss is divided over multiple years and that individuals should maintain a minimum annual consumption. In this case, there is no catastrophic flood risk and residential flood risk consists of collective and individual recoverable flood risk. The consumption loss is smoothed over 5 years and the minimum consumption is set at US\$700, which is the poverty line. If consumption was already below the poverty line, this level of consumption is set as the minimum. The results are summarized in Table 2. 


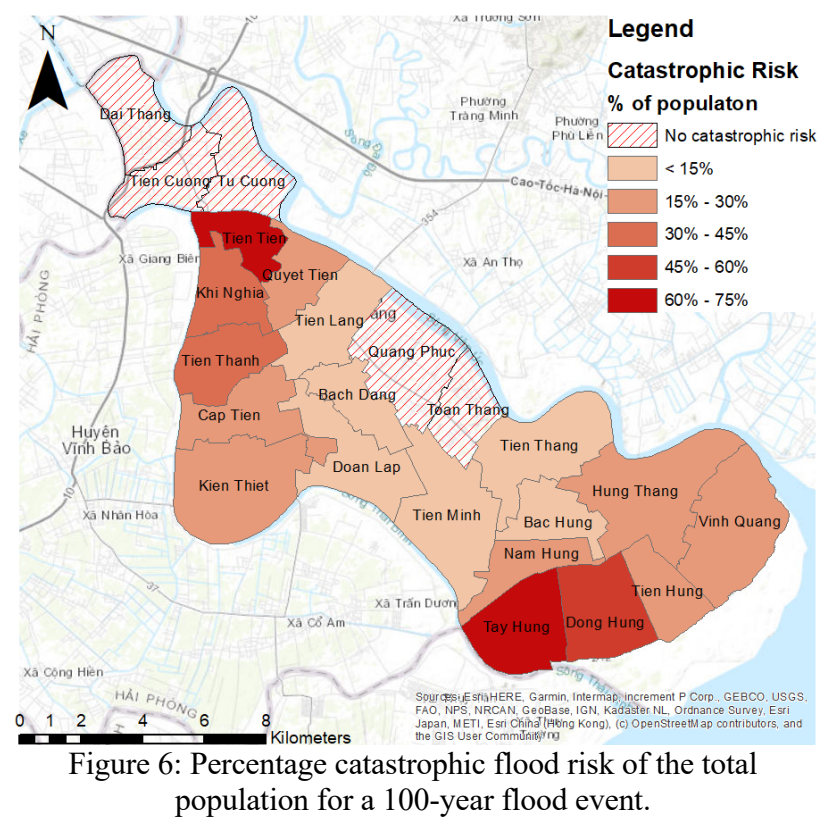

Residential flood risk is the sum of collective and individual recoverable flood risk and amounts to US\$ 1.6 million. Consumption loss below the set consumption minimum is covered by the collective flood risk. Collective flood risk is the amount of social protection that is yearly required to maintain the consumption minimum, on average. The US\$ 0.9 million of collective flood risk is therefore equal to the amount the Vietnamese government should yearly put aside if they would to decide to start a social protection fund for Tien Lang. Consumption loss above the set consumption minimum is the individual recoverable flood risk and comes down to US\$ 0.7 million. Catastrophic flood risk is zero and non-residential flood risk equals to US\$ 1.2 million. The total Expected Annual Social Welfare Loss (EASWL) sums up to US\$ 2.9 million. The financial protection rate is defined as the amount of residential flood risk that is covered through financial protection. It is calculated by dividing collective flood risk by residential flood risk. More than half of the residential flood risk is covered collectively (57\%).

By assuming social protection targeted at the poor and by taking social flood vulnerability into account, the flood risk of poor people is not underestimated. CBAs based on these social welfare benefits will therefore not be biased against FRRIs to protect the poor. Moreover, the difference in EASWL between scenario 2 and scenario 3 illustrates the large social welfare benefit of being financially protected.

If FRRMs should increase the safety standard to a 30-year flood level for the whole district, the annual flood risk reduction benefit would be US\$ 1.0 million. This would result in a total PV benefit of US\$29.1 million over the whole lifespan of the project (assuming an economic growth rate and discount rate of both $6 \%$ ). However, increasing the safety standard to a 30-year flood level does not reduce the demand for social protection. Figure 7 shows the percentage of the population that need socialprotection if a 30-year flood event would occur. Especially in the communes along the Thai Binh River many individuals should still be assisted with social protection even after a 30 -year flood event, ranging from 30-72\%.

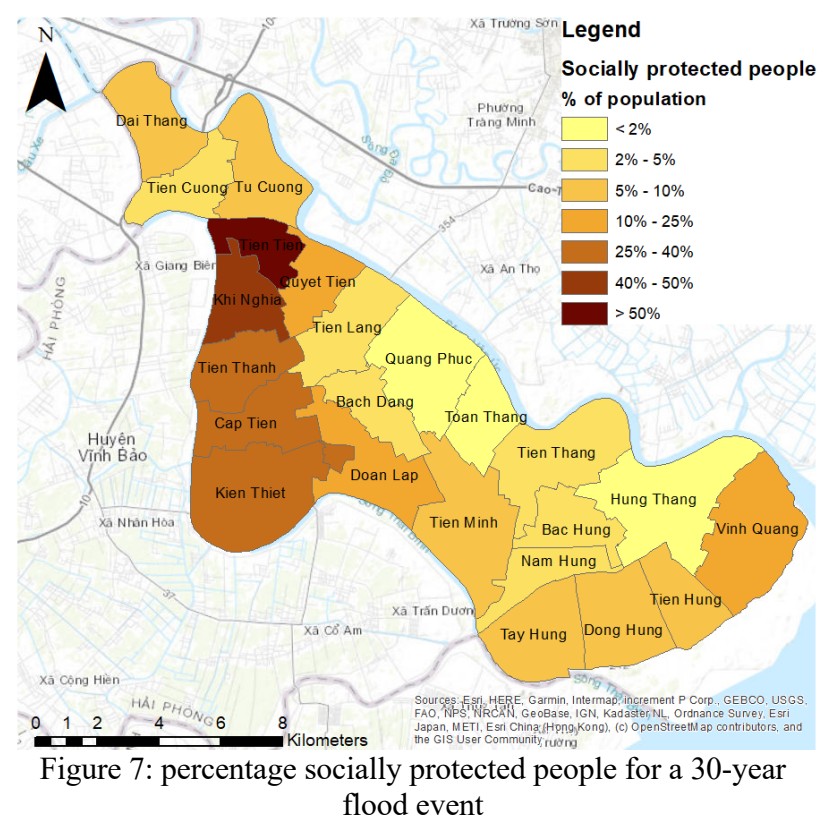

\subsection{Sensitivity analysis of CBA}

The flood risk reduction benefits of all three scenarios are used to economically evaluate FRRIs in a CBA. Given the uncertainties associated with likely benefits of the measures, the robustness of the CBA is tested in a sensitivity analysis around different values for economic growth. The results of the sensitivity analysis are summarized in Table 3. The FRRIs are robust for all three scenarios and to all levels of economic growth considered. Especially in scenario 2, the NPV and BCR are very high as the flood risk reduction enables a large social welfare benefit.

Due to COVID-19, projections of the economic growth rate for Vietnam have been decreased to $3-4 \%$ for 2020 compared to $6.5 \%$ pre-crisis projections (World Bank, 2020). Nevertheless, the positive NPV and BCR greater than 1 in scenario 3 provides evidence for the fact that a combination of physical FRRMs and risk transfer mechanisms could be a cost-effective disaster risk reduction strategy for whole of Tien Lang.

\begin{tabular}{|c|c|c|c|}
\hline \multirow[t]{2}{*}{ Scenarios } & \multirow{2}{*}{$\begin{array}{l}\text { GDP growth } \\
\text { rate }\end{array}$} & \multicolumn{2}{|c|}{ Metric } \\
\hline & & NPV & $\mathrm{BCR}$ \\
\hline \multirow[t]{3}{*}{ Scenario 1} & $3 \%$ & 10.6 & 2.2 \\
\hline & $6 \%$ & 20.4 & 3.3 \\
\hline & $9 \%$ & 37.5 & 5.3 \\
\hline \multirow[t]{3}{*}{ Scenario 2} & $3 \%$ & 336.3 & 39.2 \\
\hline & $6 \%$ & 509.8 & 58.9 \\
\hline & $9 \%$ & 813.6 & 93.5 \\
\hline \multirow[t]{3}{*}{ Scenario 3} & $3 \%$ & 10.6 & 2.2 \\
\hline & $6 \%$ & 20.3 & 3.3 \\
\hline & $9 \%$ & 37.4 & 5.2 \\
\hline
\end{tabular}

Table 3: Sensitivity of CBA indicators to protect against a 30year flood event (NPV in M\$) 


\section{Discussion}

We first evaluate the results of this research by comparing the results with the main findings of Kind et al., (2019). Both papers performed a case study in Vietnam.

The large difference in social welfare flood risk between scenario 1 and scenario 2 illustrated that traditional FRAs severely underestimate flood risk of the poor. In addition, the difference in EASWL between scenario 2 and scenario 3 emphasized the large social welfare benefit of being financially protected. These conclusions are in line with the main findings from Kind et al., (2019).

Kind et al. (2019) also found that the social welfare flood risk while assuming no financial protection could differ with a factor 30 . In this paper, we only find a factor of 18 between the first and the second scenario.

As addition to the methodology of Kind et al., (2019) we evaluated the FRRI proposed by Royal HaskoningDHV (2019a) in a CBA. The NPV and BCR for scenario 2 are very high and unrealistic. It is therefore not yet reliable to economically evaluate FRRIs based on the monetized social welfare benefits in CBAs. However, despite some of the limitations, this method can easily be applied in a multi-criteria analysis. In contrast to a CBA, a multi-criteria analysis translates absolute figures into relative values. Uncertainties in the estimated social welfare benefits are therefore less problematic. Future research should try to incorporate social welfare flood risk into MCAs for flood risk management.

\subsection{Data availability}

There are two data limitations. The first limitation is the limited availability of microeconomic data concerning financial flood protection in Vietnam. Although this is also the case for many other regions in the world, it provides a challenge to estimate the consumption loss of an individual as a result of a flood. This research applies different scenarios to assess the impact financial protection could have. Nevertheless, there is no business as usual scenario that could be used to evaluate the real life social welfare flood risk of Tien Lang. Future research should therefore focus on collecting financial protection data to be able to assess the current situation.

The second limitation is that a Monte Carlo approach is applied to assess the social welfare flood risk as there is no data on the spatial distribution of consumption. In recent years, advanced application in the field of artificial intelligence and image recognition have been developed to spatially map population density and GDP (Jean et al., 2016). It would be particularly valuable if these types of data would become available in the future.

\subsection{Assumptions}

There are four assumptions that pose limitations. Firstly, the income of an individual is set equal to the consumption. This is valid for poor people as their consumption is equal to their income (Walsh \& Hallegatte, 2020). However, non-poor people do not consume all their income, which indicates that social flood vulnerability is overestimated for non-poor people. Nevertheless, it is fairly impossible to measure income instead of consumption in developing countries due the informal economy.

Secondly, flood damages are assumed to be repaired at the cost of consumption in the same year of the flood. Individuals could choose to divide the flood damage repairs over time to smooth the impact on their consumption.

The third assumption that poses limitations is that the social flood vulnerability threshold that determines if risk is recoverable of catastrophic is set at 1 (e.g., catastrophic risk appears if the consumption loss is greater than the annual consumption). Consumption loss due to health expenditure can already be catastrophic at $40 \%$ (Xu et al., 2003), which indicates that it remains difficult to determine a proper threshold value. Nonetheless, future research could study the pre- and post-disaster situation of households to estimate their catastrophic flood risk threshold and their recovery strategy.

Finally, this research applies an indirect damage factor between $50 \%$ and $150 \%$ of the direct damage to account for income losses and health impacts. The indirect damage factor increases the social flood vulnerability and could therefore overestimate social welfare flood risk. However, the impact that floods will have on the social flood vulnerability should not be underestimated as a large percentage of the population's income is dependent on agriculture and aquaculture. On the other hand, floods can also create job opportunities during the recovery of the flood, leading to increased consumption (Nabangchang et al., 2015).

\subsection{Risk transfer mechanisms}

The results of the case study highlight the importance of risk transfer mechanisms in disaster risk reduction strategies. Traditional risk transfer mechanisms are mostly post-disaster and come in the form of insurance or social protection. In Vietnam, flood insurance penetration is low and research indicates that the demand for such a risk transfer mechanism is sparse (Reynaud et al., 2018). The situation is illustrative for many Asian countries where insurance penetration rates are low, but exposure to risk is high (Kunreuther \& Lyster, 2016). Social protection could also provide financial support in the recovery after a flood. The results of the third scenario, as described in paragraph 4.3 , indicate the potentially high social welfare benefits of being financially protected. Unfortunately, both these post-disaster risk transfer mechanisms often function too slow and are therefore not able to effectively respond and minimize the negative shock impacts of a disaster (Oxford Policy Management, 2017). Pre-disaster risk transfer mechanisms have been proven to be promising in reducing the vulnerability and increasing socioeconomic resilience of the poor. This is achieved by linking flood forecasts with social protection schemes. These practices have already been proven effective in Myanmar (Weingärtner et al., 2019).

Another innovative risk transfer mechanism is an index-based flood insurance in which the pay-out is 
triggered when it meets a certain objective meteorological or geophysical threshold. These risk transfer mechanisms are based on parametric triggers and are often established in public-private partnerships, which are collaborations between governments or supranational development banks and private insurance companies. (Kunreuther \& Lyster, 2016). Fiscal liabilities could simultaneously be reduced if such risk transfers mechanisms would be established in an international pooled catastrophe fund instead of a national disaster risk insurance (Thirawat et al., 2017). Overall, future research should focus on the pre- and post-disaster risk transfer mechanisms to build socioeconomic resilience in the face of natural disasters.

\subsection{Applications}

Over the years, the World Bank has already released many publications about the incorporation of social welfare and well-being of individuals into FRAs (Hallegatte et al., 2016, 2017; Markhvida et al., 2020; Walsh \& Hallegatte, 2020). Overall, it is promising to see the growing awareness about the concept of well-being within FRAs and CBAs. It will have a considerable impact on the future of the many communities facing natural disasters around the world.

\section{Conclusion}

Traditional FRAs and CBAs focus on asset damage and therefore often conclude that it is inefficient to protect the poor as poor people own little assets. This research aimed to apply the social welfare approach of Kind et al. (2017, 2019) to evaluate FRRIs in a CBA based on the social welfare flood risk reduction benefits and CBA parameters. A case study was performed on the district of Tien Lang in Vietnam. The quantification and monetization of the social welfare flood risk was based on Kind et al. (2017, 2019) and the case study data were adopted from Royal HaskoningDHV (2019a). A social welfare FRA was applied to assess the complex combination between flood damage, consumption loss and catastrophic loss. Data availability on financial protection was unfortunately limited. Therefore, three scenarios with different financial protection were assumed.

The first scenario assumed full financial protection and was therefore equal to a traditional FRA. It yielded an EASWL of US\$ 2.9, which was in the same order of magnitude as the flood risk of US\$ 2.6 million calculated by Royal HaskoningDHV (2019a). The second scenario assumed no form of financial protection. The total EASWL summed up to US\$ 55.6 million, with the catastrophic flood risk as largest contributor accounting for $96 \%$ of the social welfare flood risk. In case of a $100-$ year flood event, 20,000 people would have potentially died as a result of catastrophic flood risk. However, this is deemed highly unlikely as the Vietnamese government or the international community would have intervened if such human catastrophe was about to happen. The third scenario assumed targeted social protection so that all individuals could maintain a minimum consumption. The total EASWL was US\$2.9 million, which was equal to the EASWL of scenario 1.

After evaluating the FRRIs we found that it is not yet reliable to economically evaluate FRRIs based on the monetized social welfare benefits in CBAs. However, despite some of the limitations, this method can easily be applied in a MCA. Future research should try to incorporate social welfare flood risk into MCAs for flood risk management.

Despite some of the limitations of this method, it is encouraging to see that a social welfare FRA was already implemented in one of the World Bank projects of Royal HaskoningDHV. Overall, it is promising to see the growing awareness about the concept of well-being within FRAs and CBAs. Future research should focus on the preand post-disaster risk transfer mechanisms to build socioeconomic resilience in the face of natural disasters. It will have a considerable impact on the future of the many communities living in the low-lying coastal zones of the world.

\section{References}

Aerts, J. C. J. H. (2018). A review of cost estimates for flood adaptation. Water (Switzerland), 10(11). https://doi.org/10.3390/w10111646

Aerts, J. C. J. H., Botzen, W. J. W., Clarke, K. C., Cutter, S. L., Hall, J. W., Merz, B., Michel-Kerjan, E., Mysiak, J., Surminski, S., \& Kunreuther, H. (2018). Integrating human behaviour dynamics into flood disaster risk assessment. Nature Climate Change, 8(3), 193-199. https://doi.org/10.1038/s41558-018-0085-1

Andersson, H. (2018). Application of BCA in EuropeExperiences and Challenges. Journal of Benefit-Cost Analysis. https://doi.org/10.1017/bca.2018.5

Anttila-Hughes, J. K., \& Hsiang, S. M. (2013). Destruction, Disinvestment, and Death: Economic and Human Losses Following Environmental Disaster. SSRN Electronic Journal. https://doi.org/10.2139/ssrn.2220501

Asian Development Bank. (2013). Cost-Benefit Analysis for Development: A Practical Guide.

Benjamin, D., Brandt, L., \& McCaig, B. (2017). Growth with equity: income inequality in Vietnam, 2002-14. Journal of Economic Inequality. https://doi.org/10.1007/s10888-016-9341-7

Botzen, W. J. W., Kunreuther, H., \& Michel-Kerjan, E. (2015). Divergence between individual perceptions and objective indicators of tail risks: Evidence from floodplain residents in New York City. Judgment and Decision Making.

Chinh, D. T., Bubeck, P., Dung, N. V., \& Kreibich, H. (2016). The 2011 flood event in the Mekong Delta: preparedness, response, damage and recovery of private households and small businesses. Disasters. https://doi.org/10.1111/disa.12171

Cutter, S. L., Emrich, C. T., Morath, D. P., \& Dunning, C. M. (2013). Integrating social vulnerability into federal 
flood risk management planning. Journal of Flood Risk Management, 6(4), 332-344.

de Bruijn, K., Wagenaar, D., Slager, K., de Bel, M., \& Burzel, A. (2015). Updated and improved method for flood damage assessment: SSM2015 (version 2). 2015(Version 2), 96.

de Ruig, L. T., Barnard, P. L., Botzen, W. J. W., Grifman, P., Hart, J. F., de Moel, H., Sadrpour, N., \& Aerts, J. C. J. H. (2019). An economic evaluation of adaptation pathways in coastal mega cities: An illustration for Los Angeles. Science of the Total Environment, 678, 647-659. https://doi.org/10.1016/j.scitotenv.2019.04.308

Demirguc-Kunt, A., Klapper, L., Singer, D., Ansar, S., \& Hess, J. (2018). The Global Findex Database 2017: Measuring Financial Inclusion and the Fintech Revolution. In The Global Findex Database 2017: Measuring Financial Inclusion and the Fintech Revolution. https://doi.org/10.1596/978-1-4648-1259-0

Doocy, S., Daniels, A., Murray, S., \& Kirsch, T. D. (2013). The Human Impact of Floods: A Historical Review of Events 1980-2009 and Systematic Literature Review. $P L o S$

Currents. https://doi.org/10.1371/currents.dis.f4deb457904936b07c 09daa98ee8171a

European Commission. (2014). Guide to Cost-benefit Analysis of Investment Projects: Economic appraisal tool for Cohesion Policy 2014-2020. In Publications Office of the European Union. https://doi.org/10.2776/97516

General Statistics Office of Vietnam. (2018). Statistical Yearbook of Vietnam 2018. https://www.gso.gov.vn/default_en.aspx?tabid=515\&idm $\mathrm{id}=5 \&$ ItemID $=19299$

GSO. (2010). The 2009 Vietnam population and housing census: Major findings. April 1999, 29-132.

Hallegatte, S., Bangalore, M., \& Vogt-Schilb, A. C. (2016). Assessing socioeconomic resilience to floods in 90 countries. World Bank Group: Climate Change CrossCutting Solutions Area.

Hallegatte, S., Vogt-Schilb, A., Bangalore, M., \& Rozenberg, J. (2017). Unbreakable: Building the Resilience of the Poor in the Face of Natural Disasters. https://doi.org/10.1596/978-1-4648-1003-9

Hirabayashi, Y., Mahendran, R., Koirala, S., Konoshima, L., Yamazaki, D., Watanabe, S., Kim, H., \& Kanae, S. (2013). Global flood risk under climate change. Nature Climate $\quad$ Change, 3(9), 816-821. https://doi.org/10.1038/nclimate1911

Huizinga, J., de Moel, H., \& Szewczyk, W. (2017). Global flood depth-damage functions: Methodology and the Database with Guidelines. In Joint Research Centre (JRC). https://doi.org/10.2760/16510

IPCC. (2013). Working Group I Contribution to the IPCC Fifth Assessment Report, Climate Change 2013: The Physical Science Basis. Ipcc.

Islam, M. N., Malak, M. A., \& Islam, M. N. (2013). Community-based disaster risk and vulnerability models of a coastal municipality in Bangladesh. Natural Hazards, 69(3), 2083-2103. https://doi.org/10.1007/s11069-0130796-6

Jean, N., Burke, M., Xie, M., Davis, W. M., Lobell, D. B., \& Ermon, S. (2016). Combining satellite imagery and machine learning to predict poverty. Science, 353(6301), 790-794. https://doi.org/10.1126/science.aaf7894

Kind, J., Botzen, W. J. W., \& Aerts, J. C. J. H. (2017). Accounting for risk aversion, income distribution and social welfare in cost-benefit analysis for flood risk management. Wiley Interdisciplinary Reviews: Climate Change, 8(2), 1-20. https://doi.org/10.1002/wcc.446

Kind, J., Botzen, W. J. W., \& Aerts, J. C. J. H. (2019). Social vulnerability in cost-benefit analysis for flood risk management. Environment and Development Economics, 1-20. https://doi.org/10.1017/S1355770X19000275

Koks, E. E., Jongman, B., Husby, T. G., \& Botzen, W. J. (2015). Combining hazard, exposure and social vulnerability to provide lessons for flood risk management. Environmental science \& policy, 47, 42-52.

Kunreuther, H., \& Lyster, R. (2016). The role of public and private insurance in reducing losses from extreme weather events and disasters. In Asia Pacific Journal of Environmental Law. https://doi.org/10.4337/apjel.2016.01.02

Lanjouw, P., Marra, M., \& Nguyen, C. (2013). Vietnam ' $\mathrm{s}$ Evolving Poverty Map Patterns and Implications for Policy. Policy Research Working Paper, 6355(February).

Lawless, R. M. (2005). Bankruptcy Filing Rates after a Major Hurricane. Nevada Law Journal.

Markhvida, M., Walsh, B., Hallegatte, S., \& Baker, J. (2020). Quantification of disaster impacts through household well-being losses. Nature Sustainability. https://doi.org/10.1038/s41893-020-0508-7

McGranahan, G., Balk, D., \& Anderson, B. (2007). The rising tide: Assessing the risks of climate change and human settlements in low elevation coastal zones. Environment and Urbanization, 19(1), 17-37. https://doi.org/10.1177/0956247807076960

Nabangchang, O., Allaire, M., Leangcharoen, P., Jarungrattanapong, R., \& Whittington, D. (2015). Economic costs incurred by households in the 2011 Greater Bangkok flood. Water Resources Research. https://doi.org/10.1002/2014WR015982

Naqvi, A. A., \& Rehm, M. (2014). A multi-agent model of a low income economy: simulating the distributional effects of natural disasters. Journal of Economic Interaction and Coordination. https://doi.org/10.1007/s11403-014-0137-1

Neumann, B., Vafeidis, A. T., Zimmermann, J., \& Nicholls, R. J. (2015). Future coastal population growth and exposure to sea-level rise and coastal flooding - A global assessment. PLoS ONE, 10(3). https://doi.org/10.1371/journal.pone.0118571

Oxford Policy Management. (2017). Shock-Responsive Social Protection Systems Research: Literature review 
(2nd

Edition).

March. http://www.opml.co.uk/sites/default/files/Shock_responsi ve_social_protection_Literature review_EN.pdf

Pearce, D., Atkinson, G., \& Mourato, S. (2006). Costbenefit analysis and the environment: Recent developments. In Cost-benefit analysis and the environment: Recent developments. https://doi.org/10.1787/9789264010055-en

Porter, T. (1995). Cultures of Objectivity. Trust in Numbers: The Pursuit of Objectivity in Science and Public Life.

Reynaud, A., \& Nguyen, M. H. (2016). Valuing Flood Risk Reductions. Environmental Modeling and Assessment, 21(5), 603-617. https://doi.org/10.1007/s10666-016-9500-z

Reynaud, A., Nguyen, M. H., \& Aubert, C. (2018). Is there a demand for flood insurance in Vietnam? Results from a choice experiment. Environmental Economics and Policy Studies. https://doi.org/10.1007/s10018-017-0207-4

Royal HaskoningDHV. (2019a). Development of Coastal Multi-Hazard Mapping, Vulnerability and Risk Assessments and Investment Framework for Coastal Interventions in Selected Coastal Communities in Vietnam.

Royal HaskoningDHV. (2019b). Strategic Flood Risk Assessment New Yangon City.

Scussolini, P., Tran, T. T. Van, Koks, E., Diaz-Loaiza, A., Ho, P. L., \& Lasage, R. (2017). Adaptation to Sea Level Rise: A Multidisciplinary Analysis for Ho Chi Minh City, Vietnam. Water Resources Research, 53(12), 1084110857. https://doi.org/10.1002/2017WR021344

Thirawat, N., Udompol, S., \& Ponjan, P. (2017). Disaster risk reduction and international catastrophe risk insurance facility. Mitigation and Adaptation Strategies for Global Change, 22(7), 1021-1039. https://doi.org/10.1007/s11027-016-9711-2

UNDRR. (2019). Global Assessment Report on Disaster Risk Reduction, Geneva, Switzerland, United Nations Office for Disaster Risk Reduction (UNDRR). 472.

Walsh, B., \& Hallegatte, S. (2020). Measuring Natural Risks in the Philippines: Socioeconomic Resilience and Wellbeing Losses. Economics of Disasters and Climate Change, January. https://doi.org/10.1007/s41885-01900047-X

Weingärtner, L., Jaime, C., Todd, M., Levine, S., Mcdowell, S., \& Macleod, D. (2019). Reducing flood impacts through forecast-based action Entry points for social protection systems in Kenya.

Winsemius, H. C., Jongman, B., Veldkamp, T. I. E., Hallegatte, S., Bangalore, M., \& Ward, P. J. (2018). Disaster risk, climate change, and poverty: Assessing the global exposure of poor people to floods and droughts. Environment and Development Economics. https://doi.org/10.1017/S1355770X17000444

Wordpop. (2017). WorldPop, open data for spatial demography. In Scientific Data. https://doi.org/10.1038/sdata.2017.4

World Bank. (2010). Weathering the Storm: Options for Disaster Risk Financing in Vietnam. March, 130. http://documents.worldbank.org/curated/en/56919146810 8554653/Vietnam-Weathering-the-storm-options-fordisaster-risk-financing-in-Vietnam

World Bank. (2017). Rapid Flood Damage and Needs Assessment, Vietnam 2016. 42.

World Bank. (2020). Vietnam Overview. https://wwwworldbank-org.vu-

nl.idm.oclc.org/en/country/vietnam/overview

Xu, K., Evans, D. B., Kawabata, K., Zeramdini, R., Klavus, J., \& Murray, C. J. L. (2003). Household catastrophic health expenditure: A multicountry analysis. Lancet. https://doi.org/10.1016/S0140-6736(03)13861-5

Zakour, M. J., \& Gillespie, D. F. (2013). Community Disaster Vulnerability. In Community Disaster Vulnerability. https://doi.org/10.1007/978-1-4614-5737-4

Zhai, G., Sato, T., Fukuzono, T., Ikeda, S., \& Yoshida, K. (2006). Willingness to pay for flood risk reduction and its determinants in japan. Journal of the American Water Resources Association. https://doi.org/10.1111/j.17521688.2006.tb04505.x

Zhang, Y. L., \& You, W. J. (2014). Social vulnerability to floods: a case study of Huaihe River Basin. Natural Hazards, 71(3), 2113-2125. 